The Journal of Laryngology \& Otology

http://journals.cambridge.org/JLO

Additional services for The Journal of Laryngology \& Otology:

Email alerts: Click here

Subscriptions: Click here

Commercial reprints: Click here

Terms of use : $\underline{\text { Click here }}$

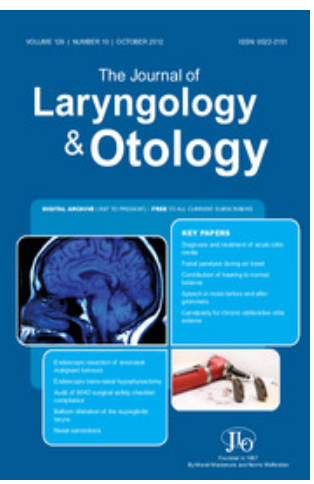

\title{
Cytomegalovirus ulceration of the oropharynx
}

\author{
P. D. French, M. A. Birchall and J. R. W. Harris
}

The Journal of Laryngology \& Otology / Volume 105 / Issue 09 / September 1991, pp 739 - 742

DOI: 10.1017/S0022215100117177, Published online: 29 June 2007

Link to this article: http://journals.cambridge.org/abstract_S0022215100117177

How to cite this article:

P. D. French, M. A. Birchall and J. R. W. Harris (1991). Cytomegalovirus ulceration of the oropharynx. The Journal of Laryngology \& Otology, 105, pp 739-742 doi:10.1017/S0022215100117177

Request Permissions : $\underline{\text { Click here }}$ 


\title{
Cytomegalovirus ulceration of the oropharynx
}

\author{
P. D. French, M.R.C.P., M. A. Birchall, F.R.C.S., J. R. W. Harris, F.R.C.P. (London)
}

\begin{abstract}
Cytomegalovirus (CMV) is a common opportunistic infection in both iatrogenic and HIV-induced immunosuppression. The usual sites of involvement are the gastro-intestinal tract, retina and lung. We present three cases of CMV ulceration of the oropharynx. All three patients presented with symptoms localized to the oropharynx and in each case the diagnosis was only made on histological examination of ulcer biopsy specimens. The patients all responded well to ganciclovir treatment and at writing none have required maintenance therapy (7-11 months post diagnosis).
\end{abstract}

\section{Case 1}

A 27-year-old homosexual man with the acquired immunodeficiency syndrome (AIDS) was admitted to hospital in October 1989 with a six-week history of proximal odynophagia, right-sided sore throat and $3 \mathrm{~kg}$ weight loss. A right tonsillar fossa ulcer had been noted four weeks earlier in the out-patient clinic and swabs taken at this time for bacterial and Herpes simplex culture were negative. He was treated empirically for oral herpes simplex with acyclovir $200 \mathrm{mg}$ five times per day for two weeks, with no response.

He was diagnosed human immunodeficiency virus (HIV1) antibody positive in February 1988. He had latent syphilis treated in 1983 and suffered from recurrent perianal Herpes simplex. In September 1988 he was treated for Pneumocystis carinii pneumonia (PCP) after which he remained symptomless (apart from occasional perianal herpes) until the onset of dysphagia.

Since the PCP he had been taking dapsone $100 \mathrm{mg} /$ pyramethamine $25 \mathrm{mg}$ weekly (as PCP prophylaxis) and zidovudine $200 \mathrm{mg}$ qds. He had been taking acyclovir $200 \mathrm{mg}$ twice daily for six months as successful perianal herpes prophylaxis and was also taking fluconazole $50 \mathrm{mg}$ daily for oral candida.

Examination revealed a shallow ulcer $(0.3 \mathrm{~cm} \times$ $0.5 \mathrm{~cm}$ ) centred on the tonsil and anterior pillar of the fauces with yellow slough at its base and a surrounding raised erythematous area (Fig. 1). There were no other oropharyngeal ulcers and ENT examination including indirect laryngoscopy was normal. General examination including fundoscopy was unremarkable apart from a low grade pyrexia (37.4C).

Biopsy of the ulcer revealed an acute inflammatory response with typical CMV inclusion bodies in the cells of the endothelium (Fig. 2).

He was treated with ganciclovir (dihydroxyprpoxymethyl guanine; DHPG) $300 \mathrm{mg}$ per day intravenously for two weeks which resulted in complete resolution of the ulcer. In the 11 months following this episode he has not required DHPG maintenance therapy.

\section{Case 2}

A 43-year-old homosexual man with AIDS presented in March 1990 with an 8 week history of odynophagia and weight loss of $6 \mathrm{~kg}$. On indirect laryngoscopy a round, $1 \mathrm{~cm}$ diameter, yellow-based ulcer with raised edges and a base of slough in the left vallecula and ulceration involving much of the ventral epiglottis was noted.

Swabs taken for bacterial and Herpes simplex culture were negative.

He was diagnosed HIV1 antibody positive in November 1988. He had secondary syphilis treated in 1979 and had single dermatomal Herpes zoster in 1982. He devel-

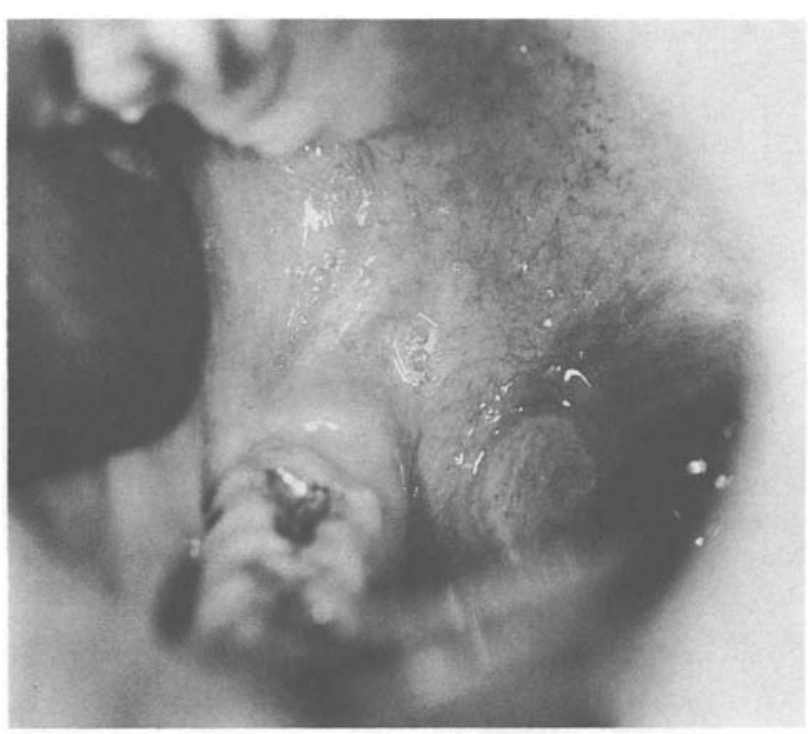

FIG. 1

Case 1 showing an ulcer on the tonsil and anterior pillar of the fauces. 

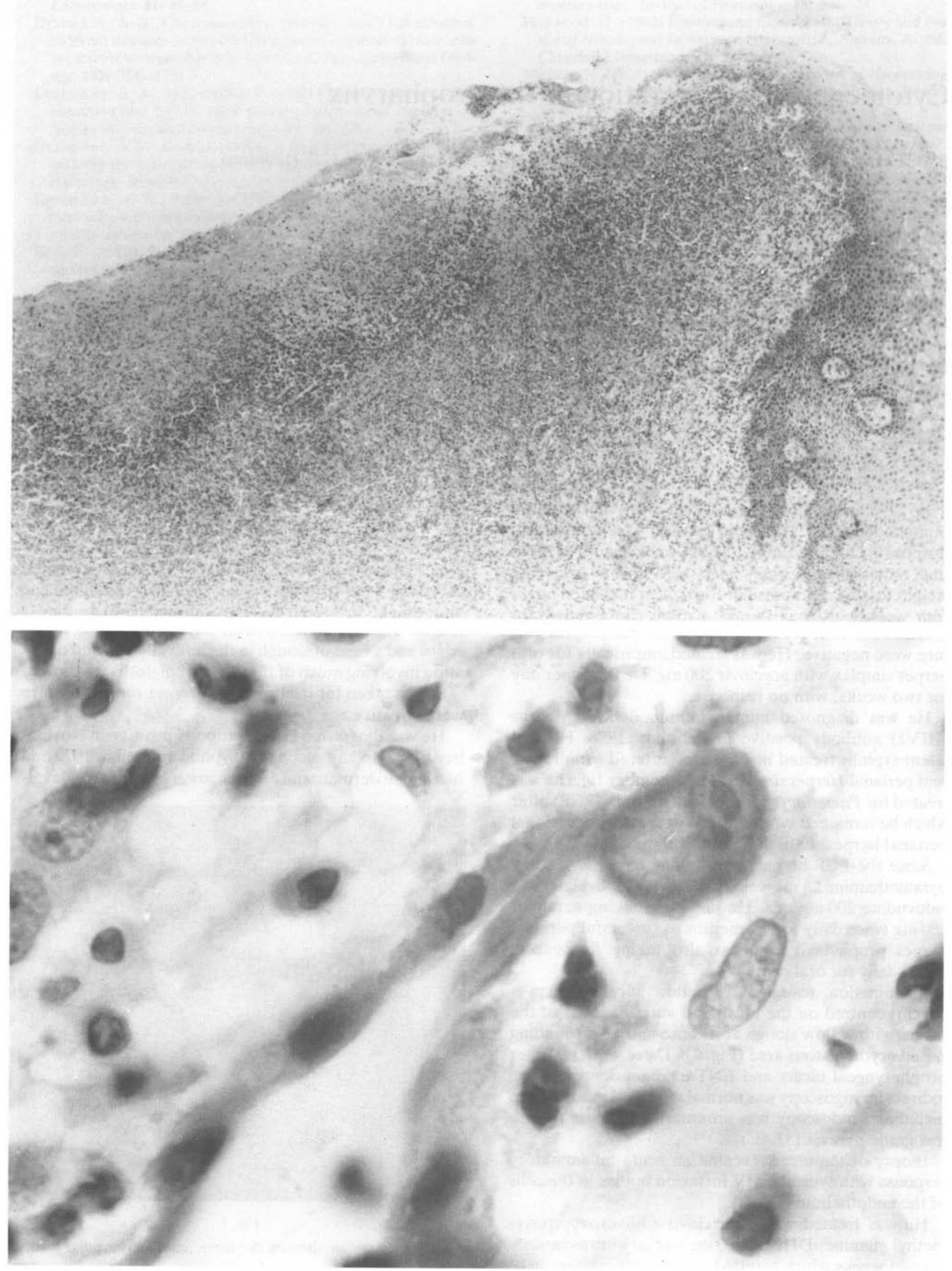

FIG. 2

Photomicrographs of tonsillar biopsy from case 1. Low power picture shows extensive polymorphonuclear cell infiltrate (a; $\times 40)$, while higher power reveals endothelial cell swelling and prominent CMV inclusion body $(\mathrm{b} ; \times 1000)$. 


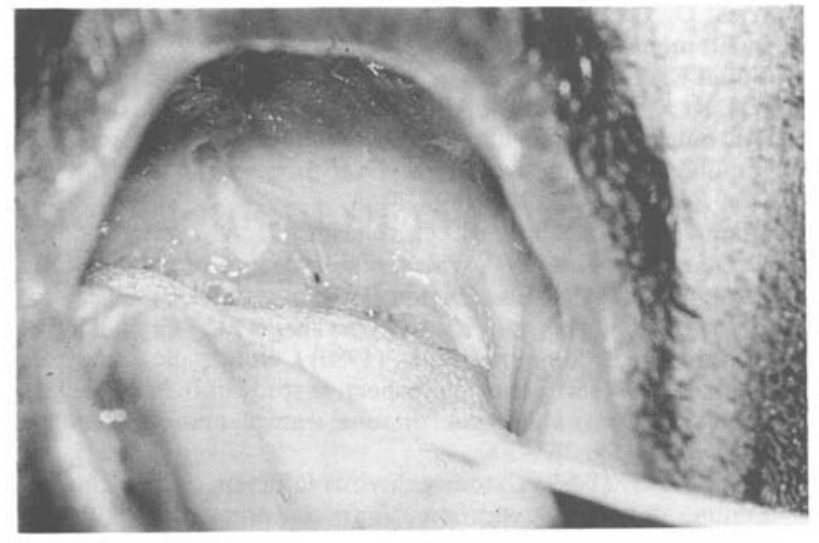

FIG. 3

Case 3 showing linear deep palatal ulceration.

oped PCP in February 1989 and lingual herpes simplex infection in March 1989 both of which responded to treatment. He later developed two lesions of Kaposi's sarcoma on his right upper arm.

His medication on admission included zidovudine $250 \mathrm{mg}$ qds which he had been taking since he developed PCP, ketoconazole $200 \mathrm{mg}$ od as oral candida prophylaxis and acyclovir $200 \mathrm{mg} \times 5 /$ day for the preceding two weeks to which his ulcer had not responded.

Examination (including fundoscopy) was unremarkable apart from the above Kaposi's sarcoma lesions. To establish a histological diagnosis, direct laryngoscopy under general anaesthesia was performed and revealed the ulcer to be a similar size to the previous examination but now with extensive erosion of the epiglottic cartilage and consequent chondritis. A biopsy of the ulcer revealed typical CMV inclusion bodies in the endothelium.

He was treated with DHPG $300 \mathrm{mg}$ daily intravenously for two weeks which resulted in complete resolution of his dysphagia. Indirect laryngoscopy performed one month after treatment revealed the epiglottis had re-epithelialized. He remains well seven months later and has not required DHPG maintenance therapy.

\section{Case 3}

A 56-year-old renal transplant recipient was transferred to this unit for assessment in October 1989 . He gave a two-week history of hoarseness, sore throat and mouth ulceration.

He gave a past history of hypertension and chronic renal failure and had undergone renal transplantation in 1987. This had been rejected and he had a second renal transplant in February 1989. Apart from his antihypertensive medication, he was receiving prednisolone $17.5 \mathrm{mg}$ daily, cyclosporin $300 \mathrm{mg}$ daily and azathioprine $500 \mathrm{mg}$ daily. A week before transfer he was commenced on empirical therapy for oral Candida and Herpes simplex with fluconazole $100 \mathrm{mg}$ orally daily and acyclovir $250 \mathrm{mg}$ intravenously daily respectively with no relief of symptoms.

Examination revealed him to be anaemic and to have a peritoneal dialysis catheter in situ. He had severe bullae formation and ulceration of the palate and oropharynx.
Direct laryngoscopy was performed under general anaesthesia. Two linear ulcers on the palate were noted (Fig. 3) as well as a swollen supraglottis with tiny superficial bullae. Biopsies from the palate, supraglottis and ventral epiglottis all revealed numerous intranuclear and intracytoplasmic inclusions consistent with CMV.

$\mathrm{He}$ was treated with DHPG $300 \mathrm{mg}$ daily intravenously for two weeks with symptomatic improvement. When reviewed one week into his DHPG treatment by indirect laryngoscopy his palatal ulcers were healing and the supraglottis was erythematous but less swollen. Ten months later he has had no recrudescence of his symptoms.

\section{Discussion}

Cytomegalovirus is a member of the herpes family of viruses and like other herpes viruses produces latent infection. Between 50 and 80 per cent of the adult population of the UK and nearly 100 per cent of HIV antibody positive homosexual men are infected with cytomegalovirus. However, serious disease associated with cytomegalovirus in adults is confined to those with immunosuppression. It is an important pathogen in both HIV-related and iatrogenic immunosuppression (Peterson, R. K., et al., 1980; Pinching, 1989). Although the most common clinical manifestations of CMV are in the retina, lung and gastrointestinal tract, a literature search reveals five case reports of CMV-associated ulceration of the oropharynx (Williams et al., 1960; Robson and Mackay, 1969; Takagi and Ishikawi, 1977; Myerson, D. et al., 1984; Kanas et al., 1987).

In HIV infection, CMV-related oropharyngeal ulceration has been described as the index diagnosis of AIDS (Kanas et al., 1987) and CMV has been implicated as a cause of recurrent laryngeal nerve palsy (Small et al., 1989). Williams et al. describe a 25 -year-old man with CMV mucosal ulceration and Pneumocystis carinii pneumonia with no obvious underlying cuase although recently a retrospective diagnosis of HIV infection has been made (Williams et al., 1960; Corbitt et al., 1990). CMV ulceration of the oropharynx has also been associated with patients receiving immunosuppressive therapy for lupoid hepatitis (Robson and Mackay, 1969) and bone marrow transplantation (Myerson et al., 1984) as well as a patient receiving chemotherapy for renal carcinoma (Takagi and Ishikawi, 1977). In only one of these patients was the diagnosis made ante mortem (Kanas et al., 1987).

Effective therapy for CMV now exists although both available drugs, DHPG and foscarnet, have significant toxicity (myelotoxicity and nephrotoxicity particularly respectively). There are many causes of oropharyngeal ulceration in immunocompromised patients and, as our cases show, CMV can present with a confusing variety of macroscopic appearances. Therefore it is vital to make a histological diagnosis. In the oropharynx, this is best achieved under general anaesthesia with good lighting and suction. It is important when undertaking this procedure to remember that this group of patients may have clotting disorders such as thrombocytopenia that might require pre-operative treatment. The differential diagnosis includes infections such as Herpes simplex (Cohen and Greenberg, 1985), Candida and, particularly in HIV 
infection, aphthous ulceration and secondary tumours such as Kaposi's sarcoma and lymphoma.

Most patients with AIDS and pathogenic CMV infection relapse after discontinuing DHPG (Jeffries, 1989). Relapse of CMV in patients with retinitis can lead to permanent visual loss and it is not therefore justified to withhold maintenance DHPG. However with the oropharyngeal ulceration of our patients, the role of maintenance DHPG is uncertain and is possibly only needed if relapse occurs. Patients with transient iatrogenic immunosuppression such as Case 3 do not usually require maintenance therapy.

In summary, CMV induced ulceration of the oropharynx is a treatable condition with significant morbidity if not diagnosed early. Biopsies of all oropharyngeal ulcers in immunocompromised patients should be taken in those who fail to respond to simple non-toxic medication.

\section{Acknowledgements}

We would like to thank Dr Kim Suvarna of the St Mary's Hospital, Department of Histopathology for the photomicrographs and the Medical Illustration Department at St Mary's Hospital Medical School for the photography.

\section{References}

Cohen, S. G., Greenberg, M. S. (1985) Chronic oral herpes simplex virus infection in immunocompromised patients. Oral Surgery, Oral Medicine, Oral Pathology, 59: 465-471.

Corbitt, G., Bailey, A. S., Williams, G. (1990) HIV infection in Manchester. Lancet, 2: 51.

\section{Key words: Key words: Cytomegalovirus, Oropharynx}

Jeffries, D. J. (1989) The spectrum of cytomegalovirus infection and its management. Journal of Antimicrobial Chemotherapy, 23 (Suppl E): 1-16.

Kanas, R. J., Jensen, J. L., Abrams, A. B., Wuerker, R. B. (1987) Oral mucosal cytomegalovirus as a manifestation of the acquired immune deficiency syndrome. Oral Surgery, Oral Medicine, Oral Pathology, 64: 183-189.

Myerson, D., Hackman, R. C., Nelson, J. A., Ward, D. C., McDougal, J. K. (1984) Widespread presence of histologically occult-cytomegalovirus. Human Pathology, 15; 430-439.

Peterson, P. K., Balfour, H. H., Marker, S. C., Fryd, D. S., Howard, R. J., Simmons, R. L. (1980) Cytomegalic diseases in renal allograft recipients: a prospective study of the clinical features, risk factors and impact on renal transplantation. Medicine (Baltimore), 59: 283-300.

Pinching, A. J. (1989) Cytomegalovirus infection in the acquired immune deficiency syndrome. Journal Antimicrobial Chemotherapy, 23 (Suppl E): 31-36.

Robson, G. S., Mackay, I. R. (1969) Generalized cytomegalovirus infection in a patient with lupoid hepatitis. Australian Annals of Medicine, 18: 147-150.

Small, P. M., McPhaul, L. W., Sooy, C. D., Wofsy, C. B., Jacobsen, M. (1989) Cytomegalovirus infection of the laryngeal nerve presenting as hoarseness in patients with the acquired immunodeficiency syndrome. American Journal of Medicine, 86: $108-110$

Takagi, M., Ishikawi, G. (1977) Double viral infection of the mouth in the cancer patient. Bull Tokyo Med Dent Univ, 24: 233-238.

Williams, G., Stretton, T. B., Leonard, J. C. (1960) Cytomegalic inclusion disease and Pneumocystics carinii pneumonia in an adult. Lancet, 2: 951-955. '

Address for correspondence:

Dr P. D. French,

Senior Registrar in Genitourinary Medicine,

James Pringle House,

The Middlesex Hospital,

London W1N 8AA 